\title{
Prevalence of Soil-Transmitted Helminths and Intestinal Protozoa among School Children in Lome, Togo
}

\author{
Monique A. Dorkenoo, ${ }^{1,2}$, Foli Agbeko ${ }^{3,4}{ }^{*}$, Harishu Dokoto5, Dave Plate, \\ Mawouto Fiawoo", Kossi Yakpa², Efoe Sossou' ${ }^{2}$, Sevi K. Sognikin 7 , \\ Adama Dodji Gbadoe ${ }^{4}$, Rachel Bronzan8
}

\author{
${ }^{1}$ Département des Sciences Fondamentales et Biologiques, Faculté des Sciences de la santé, Université de Lomé, Lomé, Togo \\ ${ }^{2}$ Division des Laboratoires, Ministère de la Santé et de l'Hygiène Publique, Lomé, Togo \\ ${ }^{3}$ Département de la Pédiatrie, Centre Hospitalier Universitaire Campus, Lomé, Togo \\ ${ }^{4}$ Département de la Pédiatrie, Faculté des Sciences de la santé, Université de Lomé, Lomé, Togo \\ ${ }^{5}$ Hôpital d'Instruction des Armées, Centre Universitaire de Cotonou, Cotonou, Benin \\ ${ }^{6}$ Hope Education Foundation, Pompano, Florida, USA \\ ${ }^{7}$ Programme National de Lutte Intégrée contre les Maladies Tropicales Négligées, Ministère de la Santé et de l'Hygiène Publique, \\ Lomé, Togo \\ ${ }^{8}$ Health and Development International, Newburyport, USA \\ Email: *folyvon@gmail.com
}

How to cite this paper: Dorkenoo, M.A. Agbeko, F., Dokoto, H., Plate, D., Fiawoo, M., Yakpa, K., Sossou, E., Sognikin, S.K., Gbadoe, A.D. and Bronzan, R. (2021) Prevalence of Soil-Transmitted Helminths and Intestinal Protozoa among School Children in Lome, Togo. Open Journal of Pediatrics, 11, 313-328.

https://doi.org/10.4236/ojped.2021.112029

Received: April 13, 2021

Accepted: June 26, 2021

Published: June 29, 2021

Copyright $\odot 2021$ by author(s) and Scientific Research Publishing Inc. This work is licensed under the Creative Commons Attribution International License (CC BY 4.0).

http://creativecommons.org/licenses/by/4.0/

cc) (i) Open Access

\begin{abstract}
Background: Significant morbidity in children is associated with infectious diseases especially soil-transmitted helminth (STH) infections which are prevalent in sub-Saharan African countries. The objective of this study is to estimate the prevalence of STH and intestinal protozoa among schoolchildren in Lomé, Togo. Patients and Methods: In November 2013, in each of the five districts of the Lomé-commune region, thirty pupils per level of the third, fourth, fifth and sixth grades of five primary schools were included. Each child submitted a single stool sample that was analyzed by the Kato-Katz method for STH. In addition, stool samples of school children selected in third and sixth grades were examined by direct visualization using saline and $\mathrm{Lu}$ gol's stain for intestinal protozoa. Results: A total of 2944 children were enrolled at 25 schools. The overall prevalence of STH at schools was 5.0\% (range 1.5\% to $8.6 \%$ ), was higher in boys than girls, and increased with age and grade. Hookworm was the most prevalent species (3.4\% of children surveyed). Intestinal protozoa were found in $52.2 \%$ (765/1465) of children tested and commensal amoebae represented $22.7 \%$ of these protozoa identified. Entamoeba histolytical dispar/moshkovskii and Giardia intestinalis were identified in $2.3 \%$ and $11.5 \%$ of children, respectively. Co-infestation was noted in $1.35 \%$
\end{abstract}


of children with intestinal helminths and $12.2 \%$ of children with protozoa. Conclusion: Although a high prevalence of intestinal protozoa was found in our study, the majority were non-pathogenic protozoa and the low prevalence of STH among school-age children in Lomé-commune region confirms that mass drug administration (MDA) is not needed. Children should receive additional education on best hygiene practices.

\section{Keywords}

Soil Transmitted Helminth, Intestinal Protozoa, Prevalence, Schoolchildren, Togo

\section{Introduction}

Soil-transmitted helminth (STH) infections and other parasitic diseases are prevalent in the world, particularly in sub-Saharan Africa. In 2017, the number of people infected in the world was estimated at 1.2 billion, with $90 \%$ of infections occurring in sub-Saharan Africa [1]. These parasites are often associated with stunted growth, micronutrient deficiency leading to decreased resistance to infection, cognitive impairment, educational difficulties among children and, later, low social and economic productivity [2]. Hookworm also causes anemia and increases maternal morbidity and low birth weight, thus maintaining a vicious cycle of morbidity and poverty [3]. School-age children (SAC) are the population most at risk, but they also contribute significantly to transmission. A key strategy recommended by WHO against these infections is morbidity control through mass drug administration (MDA) of preventive chemotherapy (PC) with albendazole or mebendazole targeting high-risk groups such as pre-school and school-age children, women of childbearing age and, since 2013, any adult at high risk [4]. PC should be conducted once per year if the prevalence in an ecological zone is between $20 \%$ and $49 \%$, twice per year if it is $50 \%$ or higher, and individualized in communities with a prevalence of less than $20 \%$ [4]. In Togo, a national baseline survey conducted in 2009 found a high prevalence of STH [5] and in 2010, MDA with albendazole targeting SAC was initiated in areas where STH prevalence was $20 \%$ or more. During this baseline survey, the health region of Lomé-commune, considered at low risk regarding the urban setting, was not evaluated. However, urban areas with high STH prevalence have been noted in the literature [6] [7]. Since reliable current data were not available for this region with $1 / 7$ of the entire population of Togo, field surveys to determine the disease prevalence within Lomé-commune were needed. This evaluation was carried out in order to assess the need for albendazole MDA in this region [8] [9] [10]. The objectives of this study were to determine the prevalence of Ancylostoma duodenale, Necator americanus, Ascaris lumbricoides and Trichiuris trichiura and the prevalence of intestinal protozoa among schoolchildren. 


\section{Patients and Method}

This was a cross-sectional, school-based survey carried out from November 4 to 25, 2013 in the five districts of Lomé-commune health region that together comprise the capital of Togo [11]. Located in the southern part of the country, Lomé covers an area of $90.59 \mathrm{Km}^{2}$ with an estimated population of $1,018,840$ inhabitants in 2018 out of a total population of 7,440,366 in Togo. The study enrolled pupils attending public primary schools in this region. For the school's selection, all of the five health districts of Lomé-Commune health region considered to be an ecological different entity, were selected. In each district, based on the following criteria, the area considered to be at high risk was chosen by mutual agreement with the district chief medical officers and the sanitation department of the Ministry of Health. These criteria are: 1) low drinking water coverage, 2) poor solid waste management, 3) poor wastewater management, and 4) low latrine coverage. High-risk areas were identified, and five schools were randomly selected in these areas in each of the five districts.

In each school, 30 students from each grade from third to sixth grade were surveyed. For each of the four classes, , the first children who presented a written parental consent form signed and who could provide a stool sample were enrolled until 30 children from the grade had been recruited. At each school, children from the equivalent of third fourth, fifth and sixth grade were enrolled. The day before the survey, a consent form was sent home to each child's parent or guardian. On the day of the study, the first 30 children in each of the four grades who had received written parental consent, who declared they had not received any anti-helminthic drugs during the month prior the study, and who were able to provide a stool sample, were surveyed. Before stool collection, a questionnaire was used to record socio-demographic information. Stool testing for STH was performed using the Kato-Katz method; one slide per child was prepared and read by a laboratory technician using standard procedures and number of eggs per gram of stool was calculated for Ascaris lumbricoides, Trichuris trichiura, and hookworm. In addition, stools samples of pupils from third and sixth grade were examined by direct microscopy and with Lugol stain for intestinal protozoa.

Data were entered into CSPro and analyzed with Microsoft Excel 2007 and SPSS (Statistical Package for the Social Sciences). The prevalence of each intestinal parasite was estimated and, for STH, the intensity of infection was estimated based on the number of eggs median per gram (epg) of stool, according to the WHO classification [12]. Pearson's Chi-square test and Fisher's exact test (in cases where the expected values are less than 5) were used to compare the prevalence. The significance threshold for all statistical tests was set at $\alpha=0.05$.

The study protocol was reviewed and approved by the Bioethics Committee for Health Research of the Togo Ministry of Health. In addition, a signed written informed consent was obtained from the parents or guardian of each pupil enrolled in the study. 
Any child who tested positive for at least one STH was treated free of charge with albendazole; those who tested positive for pathogenic intestinal protozoa received a prescription for the appropriate treatment.

\section{Results}

\subsection{Characteristics of the Study Population}

A total of 2944 students in 25 schools in the 5 districts in Lomé-commune region were enrolled. The mean age was 11 old years with a range from 7 to 16 years. Characteristics of the surveyed population are shown in Table 1.

\subsection{Prevalence of STH}

Overall, 5.0\% (148/2944) children tested positive for at least one STH. The prevalence of STH varied significatively across the five districts, from $1.5 \%$ in District $\mathrm{N}^{\circ} 1$ to $8.6 \%$ in District $\mathrm{N}^{\circ} 2(\mathrm{p}<0.0001)$ (Figure 1$)$.

Prevalence increased significantly with age; the highest prevalence was found in children over 15 years of age, $15.6 \%(p=0.0001)$ (Table 2$)$. Infection was significantly more prevalent in boys than girls $(5.7 \%$ vs. $4.4 \%$; $\mathrm{p}=0.049)$. Hookworm was the predominant STH infection with a prevalence of 3.4\%. A. lumbricoides and $T$. trichiura were each found in $0.8 \%$ of cases.

Table 1. Socio-demographic characteristics of the study population.

\begin{tabular}{|c|c|c|c|c|c|c|c|}
\hline & & District 1 & District 2 & District 3 & District 4 & District 5 & Total \\
\hline & & $\mathrm{n}(\%)$ & n (\%) & n (\%) & n (\%) & n (\%) & N (\%) \\
\hline \multirow{3}{*}{7 - 9 years } & B & $65(2.2)$ & $81(2.7)$ & $85(2.9)$ & $74(2.5)$ & $89(3.0)$ & $394(13.4)$ \\
\hline & G & $71(2.4)$ & $61(2.1)$ & $99(3.4)$ & $86(2.9)$ & $114(3.9)$ & $431(14.6)$ \\
\hline & $\mathrm{T}$ & $136(4.6)$ & $142(4.8)$ & $184(6.3)$ & $160(5.4)$ & $203(6.9)$ & $825(28.0)$ \\
\hline \multirow{3}{*}{$10-12$ years } & B & $102(3.5)$ & $180(6.1)$ & $131(4.4)$ & $135(4.6)$ & $158(5.4)$ & $706(24.0)$ \\
\hline & G & $113(3.8)$ & $145(4.9)$ & $174(5.9)$ & $175(5.9)$ & $193(6.5)$ & $800(27.2)$ \\
\hline & $\mathrm{T}$ & $215(7.3)$ & $325(11.0)$ & $305(10.3)$ & $310(10.5)$ & $351(11.9)$ & $1506(51.2)$ \\
\hline \multirow{3}{*}{13 - 15 years } & B & $51(1.7)$ & $57(1.9)$ & $45(1.5)$ & $59(2.0)$ & $59(2.0)$ & $271(9.2)$ \\
\hline & G & $56(1.9)$ & $61(2.1)$ & $51(1.7)$ & $66(2.2)$ & $82(2.8)$ & $316(10.7)$ \\
\hline & $\mathrm{T}$ & $107(3.6)$ & $118(4.0)$ & $96(3.2)$ & $125(4.2)$ & $141(4.8)$ & $587(19.9)$ \\
\hline \multirow{3}{*}{$>15$ years } & B & $2(0.1)$ & $5(0.2)$ & $6(0.2)$ & $1(0.0)$ & $2(0.1)$ & $16(0.5)$ \\
\hline & G & $4(0.1)$ & $3(0.1)$ & $1(0.0)$ & $0(0.0)$ & $2(0.1)$ & $10(0.3)$ \\
\hline & $\mathrm{T}$ & $6(0.2)$ & $8(0.3)$ & $7(0.2)$ & $1(0.0)$ & $4(0.2)$ & $26(0.8)$ \\
\hline \multirow{3}{*}{ Total } & B & $220(7.5)$ & $323(11.0)$ & $267(9.1)$ & $269(9.1)$ & $308(10.5)$ & $1387(47.1)$ \\
\hline & G & $244(8.3)$ & $270(9.2)$ & $325(11.0)$ & $327(11.1)$ & $391(13.3)$ & $1557(52.9)$ \\
\hline & $\mathrm{T}$ & $464(15.8)$ & $593(20.1)$ & $592(20.1)$ & $596(20.2)$ & 699 (23.7) & $2944(100.0)$ \\
\hline
\end{tabular}

$\mathrm{B}=$ Boys; $\mathrm{G}=$ Girls; Total $=\mathrm{B}+\mathrm{G}$. 


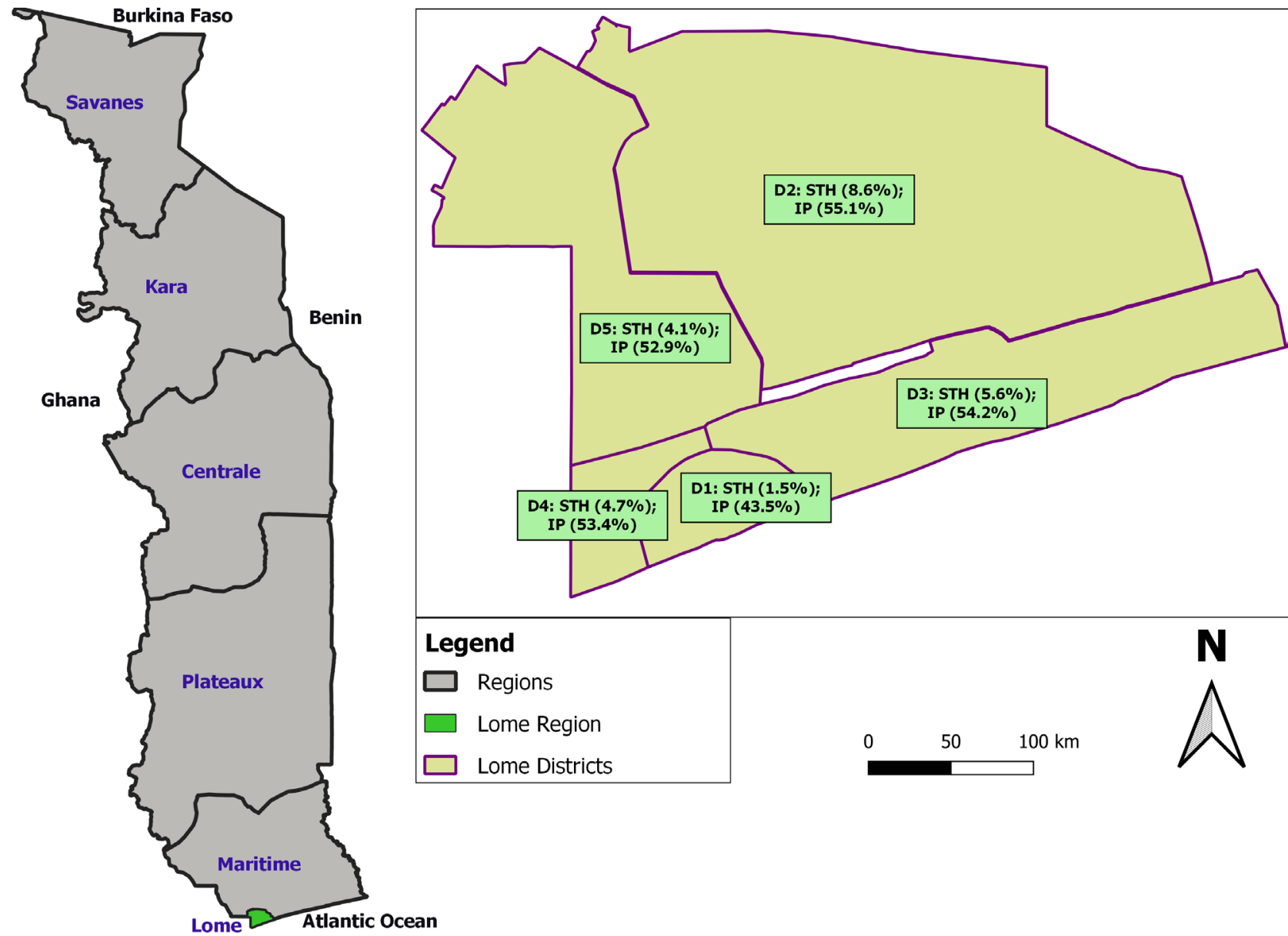

Figure 1. Prevalence of STH and intestinal protozoa (IP) per district, Lomé commune region, Togo.

Table 2. Prevalence of STH by district and age group.

\begin{tabular}{cccccc}
\hline & $7-9$ years & $10-12$ years & $13-15$ years & $\geq 15$ years & Total \\
\cline { 2 - 5 } & $\mathrm{n} / \mathrm{N}(\%)$ & $\mathrm{n} / \mathrm{N}(\%)$ & $\mathrm{n} / \mathrm{N}(\%)$ & $\mathrm{n} / \mathrm{N}(\%)$ & $\mathrm{n} / \mathrm{N}(\%)$ \\
\hline D1 & $1 / 136(0.7)$ & $3 / 215(14.0)$ & $2 / 107(1.9)$ & $1 / 6(16.7)$ & $7 / 464(1.5)$ \\
D2 & $6 / 142(4.2)$ & $29 / 325(8.9)$ & $15 / 118(12.7)$ & $1 / 8(12.5)$ & $51 / 593(8.6)$ \\
D3 & $5 / 183(2.7)$ & $18 / 307(5.9)$ & $10 / 95(10.5)$ & $0 / 7(0.0)$ & $33 / 592(5.6)$ \\
D4 & $4 / 160(2.5)$ & $15 / 310(4.8)$ & $9 / 125(7.2)$ & $0 / 1(0.0)$ & $28 / 596(4.7)$ \\
D5 & $5 / 204(2.5)$ & $19 / 350(5.4)$ & $3 / 141(2.1)$ & $2 / 4(5.0)$ & $29 / 699(4.1)$ \\
Total & $21 / 825(2.5)$ & $84 / 1507(5.6)$ & $39 / 586(6.7)$ & $4 / 26(15.4)$ & $148 / 2944(5.0)$ \\
\hline
\end{tabular}

$\mathrm{N}=$ Number of pupils surveyed; $\mathrm{D}=$ district; $\mathrm{n}=$ number of positive cases; $\mathrm{P}<0.0001$ (age); $\mathrm{P}<0.0001$ (district).

Among pupils positive for STH, hookworm represented 68.2\% (101/148) of infections. Other helminths identified were Schistosoma mansoni $(\mathrm{n}=6 ; 0.20 \%)$, Hymenolepis nana $(\mathrm{n}=3 ; 0.10 \%)$, Taenia $s p(\mathrm{n}=2 ; 0.07 \%)$ and Dicrocoelium dendriticum $(\mathrm{n}=1 ; 0.03 \%)$. Intensity of infection was mild in more than $83 \%$ of STH positive cases and in $89.1 \%$ hookworm cases. Among children with hook- 
worm infection, the egg count median per gram of stool was 239 [95\% CI 203 275] with extremes of 24 and 54,720. There were insufficient numbers of $A$. lumbricoides and T. trichiura infections to analyze intensity of infection.

\subsection{Prevalence of Intestinal Protozoa}

Stool samples from $3^{\text {rd }}$ and $6^{\text {th }}$ grade students (1465 of the 2944 students) were examined for intestinal protozoa; 52.2\% $(\mathrm{N}=765)$ were positive. Commensal amoebae were the predominant intestinal protozoa identified (22.7\%). There was no significant difference in the prevalence of intestinal protozoa by age ( $\mathrm{p}=$ $0.1968)$, grade $(\mathrm{p}=0.1194)$ (Table 3$)$ or sex $(\mathrm{p}=0.2984)$ (Table 3$)$ of the children although prevalence decreased with age among children less than 15 years old.

Children in District $\mathrm{N}^{\circ} 2$ were significantly more likely to have intestinal protozoa than were the others $\left(55.1 \%\right.$ in district $\left.\mathrm{N}^{\circ} 2 ; \mathrm{p}=0.0412\right)$ (Figure 1 ).

Among the intestinal protozoa found, the most common pathogenic protozoa were Entamoeba histolytical dispar/moshkovskii, Giardia lamblia and Trichomonas intestinalis with an overall prevalence of $17.6 \%$ (Table 4).

Table 3. Prevalence of intestinal protozoa by level of education and gender.

\begin{tabular}{|c|c|c|c|}
\hline & Boys & Girls & Total \\
\hline & $\mathrm{n} / \mathrm{N}(\%)$ & $\mathrm{n} / \mathrm{N}(\%)$ & $\mathrm{n} / \mathrm{N}(\%)$ \\
\hline $3^{\text {rd }}$ grade & $205 / 356(57.6)$ & $201 / 393(51.1)$ & $406 / 749(54.2)$ \\
\hline $6^{\text {th }}$ grade & $160 / 324(49.4)$ & $199 / 392(50.8)$ & $359 / 716(50.1)$ \\
\hline Total & $365 / 680(53.7)$ & $400 / 785(50.9)$ & $765 / 1465(52.2)$ \\
\hline
\end{tabular}

$\mathrm{N}=$ number of children surveyed; $\mathrm{n}=$ number of positive cases; $\mathrm{p}=0.1194$ (grade); $\mathrm{p}=0.2984(\mathrm{sex})$.

Table 4. Species of intestinal protozoa identified.

\begin{tabular}{|c|c|c|c|}
\hline & Parasites & $\mathbf{n}$ & Prevalence (\%) \\
\hline \multirow{5}{*}{ Amoebae } & Entamoeba histolytical dispar/ moshkovskii & 34 & 2.3 \\
\hline & Entamoeba coli & 241 & 16.5 \\
\hline & Entamoeba hartmanni & 10 & 0.7 \\
\hline & Endolimax nana & 7 & 0.5 \\
\hline & Pseudolimax butschlii & 60 & 4.1 \\
\hline \multirow{3}{*}{ Flagellates } & Giardia lamblia & 168 & 11.5 \\
\hline & Trichomonas intestinalis & 55 & 3.8 \\
\hline & Chilomastix mesnili & 13 & 0.9 \\
\hline Others & Blastocystis hominis & 160 & 10.9 \\
\hline Total & & 765 & 52.2 \\
\hline
\end{tabular}

$\mathrm{n}=$ number of positive cases. 
A few cases of polyparasitism were noted, including helminth-helminth, protozoan-protozoan and helminth-protozoa association respectively in $1.35 \%(2 / 148)$, $12.2 \%(93 / 765)$ and $2.38 \%(35 / 1465)$ of cases.

\section{Discussion}

\subsection{Prevalence of STH}

Togo's national program for the integrated control neglected tropical disease, launched in 2009, did not conduct MDA with albendazole for STH in Lomécommune because the area was considered to be at low risk based on available data. However, to ensure that all children at risk benefit from preventive chemotherapy with albendazole, it was important to measure STH prevalence in this region, where $1 / 7$ of Togo's population lives. The low overall prevalence of STH of $5.0 \%$ found in this study confirms the results previously obtained by Vovor and al. in 2008 in this same region (7.3\%) [13] but contrasts with the $32.1 \%$ found by Dorkenoo and al. [5] in 2009 during the nationwide evaluation which covered the five regions of Togo outside of Lomé-commune. Results from the present study and from Vovor et al. [13] corroborate the trend towards low STH prevalence in urban areas. Indeed, urban areas often have a relatively high level of sanitation maintained by local authorities and a high literacy rate, and residents may have a better understanding of, and compliance with, appropriate infection prevention measures. Poor environmental sanitation, limited access to latrines, unsafe water supply, low level of knowledge and practices of good individual hygiene, and low standard of living are often mentioned as major factors for the high prevalence of intestinal parasites among rural as compared to urban dwellers [14] [15]. Tchuem Tchuenté et al. in Cameroon in 2012 highlighted this, finding a significantly higher prevalence of STH in rural and peri-urban areas than in urban areas [16]. Our results also showed that the highest district-level prevalence of STH in Lomé commune (8.6\%) was indeed found in the district covering the peri-urban area of the capital. In contrast, Phiri et al. in Malawi in 2016 reported a significantly higher overall prevalence in urban than in rural areas $(16.5 \%$ vs. $3.6 \%$; $p$ 0.001) [17]. In this Malawian urban community, risk factors included having pools of water/sewage around houses $(\mathrm{OR}=$ 3.0; $\mathrm{CI}=1.4-6.5)$, not wearing shoes $(\mathrm{OR}=7.1 ; \mathrm{CI}=2.7-19.2)$, not attending school $(\mathrm{OR}=2.8 ; \mathrm{CI}=1.2-6.5)$, mothers having only $4-8$ years of education $(\mathrm{OR}=5.2 ; \mathrm{CI}=2.0-14.0)$, and mothers being below 35 years of age $(\mathrm{OR}=4.09$; $\mathrm{CI}=1.39$ - 16.28) [17]. In a Togolese study analyzing water, sanitation and hygiene (WASH) conditions in 2015, only unimproved drinking water was found to be significantly associated with the presence or absence of hookworms in an individual; however, intensity of infection (number eggs per gram of feces) was associated with availability of unimproved drinking water, availability of improved drinking water either on or off school grounds, having a handwashing station with water available, and access to a sex separate non-private or private latrine [18]. The variable distribution of these infections is therefore not always 
related to the urban or rural character of the survey area but may rather be related to the state of its environmental sanitation [15]. In addition, other factors could explain the disparity in results, especially the age of the subjects surveyed, their underlying state of health, socio-economic status and the parasitological tool and method used to identify the helminths.

The low STH prevalence in our study could also be due to the systematic deworming done in routine practice in the paediatric services of the health centers of Lomé.

The STH prevalence varied according to sex: $5.7 \%$ in boys versus $4.4 \%$ in girls $(p=0.049)$. This male predominance has been reported in several studies [19] [20], while others have noted a female predominance [8].

STH prevalence in our study also increased significantly with age $(\mathrm{p}=0.0001)$ and consequently with grade level. This result is likely due, in part, to the residual impact on the younger age groups of the albendazole deworming campaigns organized annually by the national nutrition program, with the support of UNICEF, for children under 5 years of age [21].

Hookworm was the most frequently identified helminth $(68.2 \%$ of the 148 positive cases) with a prevalence of $3.4 \%$ in our study; the same observation was made elsewhere in Togo, Benin and Côte d'Ivoire, although the rates were much higher [5] [22] [23] [24]. In this study, very low prevalence of $A$. lumbricoides and T. trichiura was found ( $0.8 \%$ for each species), confirming the results of Dorkenoo et al. in Togo in 2009 and 2015 [5] [8]. However, these results contrast with those of N'diaye et al. [20] in Senegal where A. lumbricoides and $T$. trichiura were the predominant species with a prevalence of $60 \%$ and $25.6 \%$ respectively. Local ecology and the history of distribution of ivermectin in countries co-endemic for onchocerciasis may play a role in this disparity.

The low prevalence and intensity of infestation observed in our study support the decision not to extend mass treatment with albendazole to this region of Lomé-commune.

\subsection{Prevalence of Protozoa}

The nested survey of intestinal protozoa in $3^{\text {rd }}$ and $6^{\text {th }}$ grade children was included to provide information on the prevalence of these infections, which have not previously been examined in this region; $52.2 \%$ of pupils surveyed were positive for at least one protozoan in our study. Our prevalence is higher than the $34.7 \%$ prevalence found among children under 5 years of age in South Africa [25] and $25.2 \%$ in Rwanda [26]. This difference is likely due to the fact that in our study all identified parasites (pathogenic and commensal protozoa) were accounted for, while the other authors focused their evaluations only on pathogen species. However, the prevalence of protozoa in Togo is lower than that reported in some Maghreb countries: 96.5\% in Sfax in Tunisia [27] and 88.3\% in Kenitra in Morocco [28]. This difference could be related to the diagnostic techniques (parasite concentration and/or molecular or immunological tools) used 
in these other studies versus the direct examination technique used in our study.

There was no gender difference in prevalence of protozoal infection in our study, as was also found by Sacolo-Gwebu in South Africa and Elqai in Morocco [25] [28]; there was a non-significant trend toward decreased prevalence in older grades, from $54.2 \%$ for the $3^{\text {rd }}$ grade group to $50.1 \%$ for the $6^{\text {th }}$ grade group $(\mathrm{p}=$ $0.1194)$. This decrease in infection may be due to older children practicing better individual hygiene: washing their hands, wearing shoes, losing interest in dirty games.

Prevalence of intestinal protozoa varied by district; the highest rates were observed in peri-urban areas (districts 2 and 3 ) where access to latrines is poorer and where individual and collective hygiene practices are less frequently observed.

The pathogenic species Entamoeba histolytical dispar/mishkovskii, Giardia intestinalis and Trichomonas intestinalis were found at relatively low rates, $2.3 \%$, $11.5 \%$ and $3.8 \%$ respectively. Our results are similar to those of Chekhrouhou [27] who reported these species in $2.2 \%, 17 \%$ and $1.5 \%$ respectively, and those of Ghenghesh in Libya, for the period 2000-2015, who noted 6\% of E. histolytical disparlmoshkovskii, 2\% of G. lamblia and 0.9\% of Cryptosporidium spp. [29]. Much higher prevalence of $E$. histolytica/dispar/moshkovskii has been described worldwide [29] [30]; the most commonly identified commensal species were $E$. nana and Entamoeba coli, with prevalence of $65.5 \%$ and $62.3 \%$, respectively [30], similar to our study where E. coli was the most prevalent commensal amoebae (16.5\%). In South Africa, Samie et al. were able to differentiate between the three species of the E. histolytica complex in 170 samples using the Polymerase Chain Reaction (PCR) technique and noted $15.9 \%$ E. moshkovskii, $14.7 \%$ E. dispar and 4.1\% E. histolytica [31]. This finding suggests that the proportion of pathogenic species in our study might have been much lower had we used PCR to differentiate the non-pathogenic and pathogenic species of E. histolytica complex.

The prevalence of pathogenic intestinal protozoa in our study does not constitute a public health problem in the Lomé commune health region, similar to our findings for STH.

\section{Conclusion}

The low prevalence of STH among pupils in the Lomé-commune health region shows that, despite variability between districts and schools, with urban areas having relatively lower prevalence than more rural areas, the WHO threshold for implementing albendazole mass drug administration is not reached. Low prevalence of pathogenic intestinal protozoa was also found. Intestinal parasites and especially STH, therefore, do not appear to constitute a significant public health problem in the Lomé-commune region. Nonetheless, SAC in this region should be treated three times during their primary school period in accordance with the WHO guidelines and emphasis placed on hygiene education and awareness-raising for the elimination of these intestinal parasites in Togo. 


\section{Limitations}

This work is submitted for publication after several years as a 5-year evaluative study was planned in 2018. Due to lack of funding it has not yet taken place. It was therefore imperative for us to report on the first stage of the project conducted in 2013. The data presented in this manuscript may no longer represent the current situation of the prevalence of these potentially evolving STH, but the study had the merit of showing that this health region where the Togolese capital is located does not need MDA of albendazole to SAC.

\section{Conflicts of Interest}

The authors declare no conflicts of interest regarding the publication of this paper.

\section{References}

[1] Hotez, P. and Aksoy, S. (2017) PLoS Neglected Tropical Diseases: Ten Years of Progress in Neglected Tropical Disease Control and Elimination More or Less. PLOS Neglected Tropical Diseases, 11, e0005355. https://doi.org/10.1371/journal.pntd.0005355

[2] Gall, S., Müller, I., Walter, C., Seelig, H., Steenkamp, L., Pühse, U., et al. (2017) Associations between Selective Attention and Soil-Transmitted Helminth Infections, Socioeconomic Status, and Physical Fitness in Disadvantaged Children in Port Elizabeth, South Africa. PLOS Neglected Tropical Diseases, 11, e5573. https://doi.org/10.1371/journal.pntd.0005573

[3] Pullan, R.L., Gitonga, C., Mwandawiro, C., Snow, R.W. and Brooker, S.J. (2013) Estimating the Relative Contribution of Parasitic Infections and Nutrition for Anaemia among School-Aged Children in Kenya. BMJ Open, 3, e001936. https://doi.org/10.1136/bmjopen-2012-001936

[4] WHO (2017) Guideline: Preventive Chemotherapy to Control Soil-Transmitted Helmith Infections in At-Risk Population Groups. Geneva.

[5] Dorkenoo, A.M., Bronzan, R.N. and Ayena, K.D. (2012) Nationwide Integrated Mapping of Three Neglected Tropical Diseases in Togo: Countrywide Implementation of a Novel Approach. Tropical Medicine \& International Health, 17, 896-903. https://doi.org/10.1111/j.1365-3156.2012.03004.x

[6] Sissinto-Savi de Tové, Y., Ogouyemi Hounto, A., Attinsounon, C.A., Affolabi, D., Damien, G.B. and Tchankpan, F. (2017) Prevalence des parasitoses intestinales au CNHU-HKM de Cotonou, Sud du Benin de 2003 à 2015. Journal de la Recherche Scientifique de l'Université de Lomé (Togo), 19, 437-444.

[7] Bronzan, R.N., Dorkenoo, A.M., Agbo, Y.M., Halatoko, W., Layibo, Y., Yakpa, K., Sossou, E., Adjeloh, P., Teko, M., Sossou, E., Yakpa, K., Tchalim, M., Datagni, G., Seim, A. and Sognikin, K.S. (2018) Impact of Community-Based Integrated Mass Drug Administration on Schistosomiasis and Soil-Transmitted Helminths Prevalence in Togo. PLOS Neglected Tropical Diseases, 12, e0006551. https://doi.org/10.1371/journal.pntd.0006551

[8] Dorkenoo, A., Gani, T.K., Layibo, Y., Agbo, M.Y., Dare, L.O. and Sego, A. (2018) Prévalence des parasites intestinaux à la prison civile de Lomé au Togo. African Journal of Medical Biology, 3, 415-423.

[9] Djadou, K.E., Koffi, K.S., Tsolenyanu, E., Nomboh, A., Gbadoe, A. and Atakouma, 
Y.D. (2015) Profil des parasitoses intestinales chez l'enfant a l'hopital de Tsevie (Togo). Journal de la Recherché Scientifique de l'Université de Lomé (Togo), 17, 207-211.

[10] Djibril, M.A., Bagny, A., Bouglouga, O., M’Ba, F., Redah, D. and Agbetra, A. (2010) Parasitoses Digestives: Aspects épidemiologique et étiologique dans le service d'hepato-gastro-enterologie du Chu-Campus de Lome. Journal de la Recherché Scientifique de l'Université de Lomé( Togo), 12, 273-280.

https://doi.org/10.4314/jrsul.v12i2.68114

[11] Ministere de la Santé et de l'Hygiène Publique/Division de l'information sanitaire (2019) Annuaire des statistiques sanitaires au Togo pour l'année 2018.

[12] WHO (2010) Operational Guide to Mapping of Schistomiasis and Soil-Transmitted Helminthiasis and Evaluation of Control Programmes.

[13] Vovor, A., Lawson, E. and Sossou, E. (2008) Anémie et parasitoses intestinales en milieu scolaire dans la commune de Lomé au Togo. Journal de la Société de Biologie Clinique, 12, 5-10.

[14] Sitotaw, B., Mekuriaw, H. and Damtie, D. (2019) Prevalence of Intestinal Parasitic Infections and Associated Risk Factors among Jawi Primary School Children, Jawi Town, Northwest Ethiopia. BMC Infectious Diseases, 19, 341-350. https://doi.org/10.1186/s12879-019-3971-x

[15] Alvarez Di Fino, E.M., Rubio, J., Abril, M.C., Porcasi, X. and Periago, M.V. (2020) Risk Map Development for Soil-Transmitted Helminth Infections in Argentina. PLOS Neglected Tropical Diseases, 14, e0008000. https://doi.org/10.1371/journal.pntd.0008000

[16] Tchuem Tchuenté, L.A., Romuald, I.K.N., Sumo, L., Ngassam, P., et al. (2012) Mapping of Schistosomiasis and Soil-Transmitted Helminthiasis in the Regions of Centre, East and West Cameroon. PLOS Neglected Tropical Diseases, 6, e1553. https://doi.org/10.1371/journal.pntd.0001553

[17] Phiri, K., Graham, C.J. and Ssembatya-Lule, G. (2000) Urban/Rural Differences in Prevalence and Risk Factors for Intestinal Helminth Infection in Southern Malawi. Annals of Tropical Medicine \& Parasitology, 94, 381-387. https://doi.org/10.1080/00034983.2000.11813553

[18] Baker, J.M., Trinies, V., Bronzan, R., Dorkenoo, A.M., Garn, J.V., Sognikin, S., et al. (2018) The Associations between Water and Sanitation and Hookworm Infection Using Cross-Sectional Data from Togo's National Deworming Program. PLOS Neglected Tropical Diseases, 12, e0006374. https://doi.org/10.1371/journal.pntd.0006374

[19] Dada, E.O. (2016) Prevalence of Human Intestinal Helminthes among Primary School Children in Ipogun, Ifedore Local Government Area Nigeria. Journal of Global Biosciences, 5, 3401-3407.

[20] N'diaye, D., N'diaye, M., Gueye, P.A.L., Badiane, A., et al. (2013) Prévalence des helminthoses digestives diagnostiquées à l'hôpital le Dantec de Dakar, Sénégal. Médecine et Santé Tropicale, 23, 35-38. https://doi.org/10.1684/mst.2013.0141

[21] Gebretsedik, G. (2016) Prevalence of Intestinal Parasite Associated Risk Factors among School Children of Homesha District (Worda) in Benishagul-Gumuz Regional State Western Ethiopian. Journal of Family Medicine and Health Care, 2, 57-64. https://doi.org/10.11648/j.jfmhc.20160204.16

[22] Ministère de la santé (2008) Rapport du projet pilote du traitement intégré contre les Maladies Tropicales Négligées dans le district de la Binah au Togo.

[23] Ibikounlé, M., Gbédjissi, G.L., Ogouyémi-Hounto, A., Batcho, W., et al. (2014) Schistosomose et géohelminthose dans le Nord-Est du Bénin: Cas des écoliers des 
communes de Nikki et de Pèrèrè. Bulletin de la Société de Parasitologie exotique, 107, 171-176. https://doi.org/10.1007/s13149-014-0344-y

[24] Yapi, B., Chammartin, F., Hürlimann, E., Houngbedji, C.A., N’Dri, P.B., Silué, K.D., et al. (2016) Bayesian Risk Profiling of Soil-Transmitted Helminth Infections and Estimates of Preventive Chemotherapy for School-Aged Children in Côte d'Ivoire. Parasites \& Vectors, 9, 162. https://doi.org/10.1186/s13071-016-1446-0

[25] Sacolo-Gwebu, H., Chimbari, M. and Kalinda, C. (2019) Prevalence and Risk Factors of Schistosomiasis and Soil-Transmitted Helminthiases among Preschool Aged Children (1-5 Years) in Rural KwaZulu-Natal, South Africa: A Cross-Sectional Study. Infectious Diseases of Poverty, 8, 47. https://doi.org/10.1186/s40249-019-0561-5

[26] Rujeni, N., Morona, D., Ruberanziza, E. and Mazigo, H.D. (2017) Schistosomiasis and Soil Transmitted Helminthiasis in Rwanda: An Update on Their Epidemiology and Control. Infect Diseases of Poverty, 6, 8-12.

https://doi.org/10.1186/s40249-016-0212-Z

[27] Cheikhrouhou, F., Trabelsi, H., Sellami, H., Makni, F. and Ayadi, A. (2009) Digestive Parasites in Sfax (South of Tunisia): A Retrospective Study. Revue Tunisienne d infectiologie, 3, 14-18.

[28] Elqaj, M., Belghyti, D., Ahami, A., Loutfi, H., Elkharrim, K. and Taboz, Y. (2009) Prévalence des parasitoses intestinales chez les écoliers en milieu rural à Kénitra, Maroc. World Journal of Biological Research, 2, 1-6.

http://www.wjbr.interscholar.org

[29] Ghenghesh, K.S., Ghanghish, K., Ben Darif, E.T., Shembesh, K. and Franka, E. (2016) Prevalence of Entamoeba histolytica, Giardia lamblia, and Cryptosporidium spp. in Libya: 2000-2015. Libyan Journal of Medicine, 11, e32088. https://doi.org/10.3402/ljm.v11.32088

[30] Ouattara, M., N'Guessan, N.A., Yapi, A. and N'Goran, A.K. (2010) Prevalence and Spatial Distribution of Entamoeba histolytica/Dispar and Giardia lamblia among Schoolchildren in Agboville Area (Cote d'Ivoire). PLOS Neglected Tropical Diseases, 4, e574. https://doi.org/10.1371/journal.pntd.0000574

[31] Samie, A., Mahlaule, L., Mbati, P., Nozaki, T. and ElBakri, A. (2020) Prevalence and Distribution of Entamoeba Species in a Rural Community in Northern South Africa. Food and Waterborne Parasitology, 18, e00076. https://doi.org/10.1016/j.fawpar.2020.e00076 


\section{Questionnaire 1}

District:........... Ecole:............................... Classe:.

Formulaire de collecte des données d'analyses biologiques (examen direct)

\begin{tabular}{|c|c|c|c|c|c|c|c|c|c|c|c|}
\hline \multirow{2}{*}{$\mathrm{N}^{\circ}$} & \multirow{2}{*}{$\mathrm{N}^{\circ}$ d'identification } & \multirow{2}{*}{$\begin{array}{l}\text { Age } \\
\text { (ans) }\end{array}$} & \multicolumn{2}{|c|}{ sexe } & \multicolumn{6}{|c|}{ Résultats d'examen de selles } & \multirow{2}{*}{ Observations } \\
\hline & & & F & $\mathbf{M}$ & Post & Nég & Parasites & F. végétatives & Kystes & CEufs/larves & \\
\hline 1 & & & & & & & & & & & \\
\hline 2 & & & & & & & & & & & \\
\hline 3 & & & & & & & & & & & \\
\hline 4 & & & & & & & & & & & \\
\hline 5 & & & & & & & & & & & \\
\hline 6 & & & & & & & & & & & \\
\hline 7 & & & & & & & & & & & \\
\hline 8 & & & & & & & & & & & \\
\hline 9 & & & & & & & & & & & \\
\hline 10 & & & & & & & & & & & \\
\hline
\end{tabular}

Nom et Prénoms Technicien de laboratoire

Date. 


\section{Questionnaire 2}

\begin{tabular}{|l|l|l|l|}
\hline District & \multicolumn{2}{l|}{ Ecole: } & Code Ecole: \\
\hline Classe: & \multicolumn{1}{|l|}{ Phase d'Evaluation: } \\
\hline Enseignant: & Cartographie & Post 1 & $/$ \\
\hline
\end{tabular}

\begin{tabular}{|c|c|c|c|c|}
\hline & Etiquette ID & Nom et prénoms de l'élève & Age & Sexe \\
\hline 1 & & & & $\begin{array}{l}\square \mathbf{F} \\
\square \mathbf{G}\end{array}$ \\
\hline 2 & & & & $\begin{array}{l}\square \mathbf{F} \\
\square \mathbf{G}\end{array}$ \\
\hline 3 & & & & $\begin{array}{l}\square \mathbf{F} \\
\square \mathrm{G}\end{array}$ \\
\hline 4 & & & & $\begin{array}{l}\square \mathbf{F} \\
\square \mathbf{G}\end{array}$ \\
\hline 5 & & & & $\begin{array}{l}\square \mathbf{F} \\
\square \mathrm{G}\end{array}$ \\
\hline 6 & & & & $\begin{array}{l}\square \mathbf{F} \\
\square \mathbf{G}\end{array}$ \\
\hline 7 & & & & $\begin{array}{l}\square \mathbf{F} \\
\square \mathbf{G}\end{array}$ \\
\hline 8 & & & & $\begin{array}{l}\square \mathbf{F} \\
\square \mathbf{G}\end{array}$ \\
\hline 9 & & & & $\begin{array}{l}\square \mathbf{F} \\
\square \mathbf{G}\end{array}$ \\
\hline 10 & & & & $\begin{array}{l}\square \mathbf{F} \\
\square \mathbf{G}\end{array}$ \\
\hline
\end{tabular}

Nom, prénoms et signature du chef d'équipe 


\section{Questionnaire 3}

\begin{tabular}{|l|l|l|l|}
\hline \multicolumn{2}{|l|}{ REGION: } & \multicolumn{2}{l|}{ DISTRICT: } \\
\hline ECOLE: & \multicolumn{2}{l|}{ Code Ecole: } & \multicolumn{2}{l|}{ DATE: } \\
\hline CLASSE: & \multicolumn{2}{|l}{ Phase d'Evaluation: } \\
\hline ENSEIGNANT: & Cartographie & Post intervention 1 & Post intervention 2 \\
\hline
\end{tabular}

\begin{tabular}{|c|c|c|c|c|c|c|}
\hline \multirow{3}{*}{$\begin{array}{c}\text { Person ID } \\
\text { (Mettre l'étiquette ici) }\end{array}$} & \multicolumn{6}{|c|}{ SELLES } \\
\hline & \multicolumn{5}{|c|}{ GEOHELMINTHES } & \multirow{2}{*}{ AUTRES } \\
\hline & & & Ankylostome & Ascaris & Trichocéphale & \\
\hline 1 & - & + & & & & \\
\hline 2 & - & + & & & & \\
\hline 3 & - & + & & & & \\
\hline 4 & - & + & & & & \\
\hline 5 & - & + & & & & \\
\hline 6 & - & + & & & & \\
\hline 7 & - & + & & & & \\
\hline 8 & - & + & & & & \\
\hline 9 & - & + & & & & \\
\hline 10 & - & + & & & & \\
\hline
\end{tabular}

Nom, prénoms et signature du technicien de laboratoire 


\section{Questionnaire 4}

\section{ENQUETE BIOLOGIQUE/CARTOGRAPHIE}

Date de l'enquête:

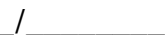

District:

Nom d'école:

Code Ecole:

Directeur Ecole

\begin{tabular}{|l|l|l|l|l|}
\hline & CE1 & CE2 & CM1 & CM2 \\
\hline Nombre d'enfants de la classe: & & & & \\
\hline Nombre avec consentement: & & & & \\
\hline Nombre refus de consentement & & & & \\
\hline Nombre ayant donné les selles & & & & \\
\hline Nombre avec selles en quantité insuffisante & & & & \\
\hline Nombre n'ayant pas donné les selles & & & & \\
\hline
\end{tabular}

Nom prénoms et signature du chef d'équipe 